\title{
POLÍTICAS PÚBLICAS, ENTROPIA E A JUDICIALIZAÇÃO DA SAÚDE PARA A OBTENÇÃO DE MEDICAMENTOS ONCOLÓGICOS: O EXEMPLO DO ESTADO DO RIO GRANDE DO SUL
}

\author{
PUBLIC POLICIES, ENTROPY AND THE JUDICIALIZATION OF HEALTH FOR OBTAINING \\ ONCOLOGICAL MEDICINES: THE STATE OF RIO GRANDE DO SUL EXAMPLE
}

\begin{abstract}
Mártin Haeberlin
Doutor em Direito (PUCRS). Mestre em Direito do Estado (PUCRS). Graduado em Direito (PUCRS). Pós-Doutorado em andamento em Economia (UFRGS), com bolsa da CAPES.

Pesquisador Visitante do Max-Planck-Institut für ausländisches öffentliches Recht und Völkerrecht. Professor da Graduação e do Mestrado em Direitos Humanos do Centro Universitário Ritter dos Reis.

E-mail: mphaeberlin@gmail.com
\end{abstract}

\section{John de Lima Fraga Jr.}

\begin{abstract}
Especialista em Direito do Estado pela Universidade Federal do Rio Grande do Sul - UFRGS (2006). Graduado em Ciências Jurídicas e Sociais pela Universidade do Vale do Rio dos Sinos - UNISINOS (2004). Membro do Conselho Superior da Procuradoria-Geral do Estado. Coordenador da $5^{\text {a }}$ Procuradoria Regional (2017/2019). Procurador do Estado do Rio Grande do Sul. E-mail: john.fragajunior@gmail.com

\section{Sandra Regina Martini}

Doutorado em Evoluzione dei Sistemi Giuridici e Nuovi Diritti pelo Università Degli Studi di Lecce, Itália(2001). Coordenadora do Mestrado em Direitos Humanos do Centro Universitário Ritter dos Reis. Professora visitante da Universidade Federal de Mato Grosso do Sul (MS).

E-mail: srmartini@terra.com.br
\end{abstract}

Recebido em: 13/02/2020

Aprovado em: 08/04/2020

RESUMO: O presente estudo trata da judicialização da saúde para a obtenção de medicamentos oncológicos, em especial no Estado do Rio Grande do Sul, considerando uma justificativa estatística alarmante: o aumento exponencial de ações judiciais para fornecimento de medicamentos, consultas, cirurgias e internações para o tratamento do câncer no Estado, em números representativos de um sério problema de saúde pública que afeta a realização de políticas públicas voltadas à efetividade deste e de outros direitos humanos e fundamentais. Valendo-se de metodologia dedutiva de caráter bibliográfico e exploratório, parte-se da hipótese de que, em alguma medida, o aporte teórico das chamadas "políticas públicas de mérito", notadamente ao tratar do mandamento de menor entropia, pode ser relevante para o entendimento de alguns dos problemas relacionados a essa excessiva utilização da via judicial. Ao final, conclui-se que a judicialização é, de fato, indicativa de falha no funcionamento da política pública, com consequências no campo jurídico e no campo econômico. Desse modo, não é respeitado, nessa política pública, o mandamento de menor entropia, porquanto se percebe, além da incipiência de ações prospectivas propostas, os reflexos negativos das ações retrospectivas, gerando um círculo vicioso de desorganização administrativa e de desperdício de recursos financeiros e humanos. 
Palavras-chave: Políticas Públicas. Entropia. Judicialização da saúde. Medicamentos oncológicos.

ABSTRACT: The present study deals with the judicialization of health in order to obtain cancer drugs, especially in the State of Rio Grande do Sul, considering an alarming statistical justification: the exponential increase in lawsuits for the supply of medicines, consultations, surgeries and hospitalizations for the treatment of cancer in this State, in numbers representing a serious public health problem that affects the implementation of public policies aimed at the effectiveness of this and other human and fundamental rights. Using a deductive methodology of bibliographic and exploratory character, we start from the hypothesis that, to some extent, the theoretical contribution of the so-called "public policies of merit", notably when dealing with the command of less entropy, may be relevant to the understanding of some of the problems related to this excessive use of the judicial system. In the end, it is concluded that judicialization is, indeed, indicative of a failure in the functioning of public policy, with consequences in the legal and economic fields. Thus, in this public policy, the commandment of less entropy is not respected, as it is perceived, in addition to the incipience of proposed prospective actions, the negative reflexes of retrospective actions, generating a vicious circle of administrative disorganization and waste of economic and human resources.

Keywords: Public Policies. Entropy. Judicialization of health. Oncological drugs.

SUMÁRIO: Introdução; 1 Por uma definição de políticas públicas; 2 A noção de entropia e sua importância para as políticas públicas; $3 \mathrm{O}$ direito à saúde e a política pública de fornecimento de medicamentos; 4 A Política Pública Para O Tratamento Do Câncer E A Ausência De Listas De Fornecimento De Medicamentos; 5 Panorama Das Ações Judiciais Para Obtenção De Medicamentos Oncológicos No Estado Do Rio Grande Do Sul; Conclusão; Referências.

\section{INTRODUÇÃO}

Às vezes, os fatos falam. Outras, exigem que se fale sobre eles. Mas isso não impede um terceiro gênero: aquele no qual os fatos falam e, ao mesmo tempo, exigem que se fale sobre eles. Este é o caso do objeto do presente estudo, que trata da judicialização da saúde para a obtenção de medicamentos oncológicos, em especial no Estado do Rio Grande do Sul, cuja justificativa, em parte, é estatística.

Isso porque, segundo dados que serão minudenciados no corpo do texto, o número de ações judiciais para fornecimento de medicamentos, consultas, cirurgias e internações para o tratamento do câncer vem crescendo no Estado do Rio Grande do Sul. Atualmente, tramitam 9.304 processos ajuizados em face do Estado relacionados ao tema. Esse número é representativo de um sério problema de saúde pública que, direta ou indiretamente, afeta a realização de políticas públicas voltadas à efetividade deste e de outros direitos humanos e fundamentais.

Diante desse cenário, o presente estudo parte da hipótese de que, em alguma medida, o aporte teórico das chamadas "políticas públicas de mérito", notadamente ao tratar do mandamento de menor entropia, pode ser relevante para o entendimento de alguns dos problemas relacionados a essa excessiva utilização da via judicial.

A análise dessa hipótese vale-se de metodologia dedutiva (análise do recorte epistemológico do fornecimento de medicamentos oncológicos desde a premissa teórica da menor entropia) de caráter bibliográfico e exploratório e é desenvolvida em plano de trabalho dividido em cinco partes: na primeira, identificam-se algumas características essenciais do conceito de políticas públicas; na segunda, essas políticas são relacionadas ao interesse público, propondo-se a utilização 
de referencial teórico das chamadas "políticas de mérito", que possuem, dentre outros mandamentos, aquele da menor entropia; na terceira, identifica-se como o legislador ordinário organizou a política pública de saúde na área da assistência farmacêutica; na quarta, analisa-se a política pública para o tratamento do câncer, com ênfase na ausência de listas de fornecimento de medicamentos para a referida doença; e na quinta traça-se um panorama das ações judiciais para obtenção de medicamentos oncológicos no Estado do Rio Grande do Sul.

Em que pese o objetivo geral deste estudo seja a análise da referida hipótese de trabalho, é possível dizer que cada uma das partes sustenta um objeto específico. Vistas em panorama, tais objetivos revelam ainda um outro: a possibilidade de ainda dizer coisas novas em temas sobre os quais muito já foi dito.

\section{POR UMA DEFINIÇÃO DE POLÍTICAS PÚBLICAS}

As políticas públicas ganharam centralidade em diversos campos de estudo, e isso vem se intensificando exponencialmente. Apenas a título de ilustração, nos últimos cinco anos, o número de trabalhos indexados na Biblioteca do Senado Federal sobre o tema triplicou, contando-se hoje mais de dez mil trabalhos relacionados ao termo.

Curiosamente, a crescente atenção que se dá as políticas públicas parece ainda não ter refletido sua apropriação pela dogmática jurídica, o que se diz em dois sentidos. Primeiro, o fato de o tema das políticas públicas não ter ganho um espaço autóctone na grande maioria dos Manuais do Direito, especialmente o Direito Administrativo, disciplina que lhe contempla como objeto. Segundo, o fato de que os trabalhos, usualmente monográficos, sobre políticas públicas, em que pese sua qualidade ${ }^{1}$, costumam pressupor o conceito de política pública para as discussões específicas que neles são realizadas. Usualmente, lê-se uma referência implícita de políticas públicas como sinônimas de atividade administrativa. Outros autores, inclusive, fazem uma identificação entre atividade administrativa e políticas públicas expressamente. É o caso de Eros Roberto Grau, para quem

[a] expressão políticas públicas designa todas as atuações do Estado, cobrindo todas as formas de intervenção do poder público na vida social [...] E de tal forma isso se institucionaliza que o próprio direito, neste quadro, passa a manifestar-se como um política pública - o direito é também, ele próprio, uma política pública. ${ }^{2}$

Partindo do pressuposto de que o acordo semântico (definição de um objeto) é um passo necessário de qualquer análise, e buscando evitar noções demasiadamente alargadas desse objeto, como a citada, colhe-se inicialmente, dentre os autores pátrios, o conceito de Maria Paula Dallari Bucci, em cujo trabalho precursor as políticas públicas são delineadas como "[...] programas de ação governamental visando a coordenar os meios à disposição do Estado e as atividades privadas,

\footnotetext{
${ }^{1}$ À guisa de exemplo, essa afirmação é referendada nos seguintes excelentes estudos: BREUS, Thiago Lima. Políticas Públicas no Estado Constitucional: problemática da concretização dos direitos fundamentais pela Administração Pública brasileira contemporânea. Belo Horizonte: Fórum, 2007; BUCCI, Maria Paula Dallari. Direito Administrativo e Políticas Públicas. São Paulo: Saraiva, 2002; BUCCI, Maria Paula Dallari (org.). Políticas Públicas: reflexões sobre o conceito. São Paulo: Saraiva, 2006; BUCCI, Maria Paula Dallari. Controle judicial de políticas públicas: possibilidades e limites. In: Fórum Administrativo: Direito Público, Belo Horizonte, v. 9, n. 103, set. 2009. Disponível em: <http://bdjur.stj.jus.br/dspace/handle/2011/32047>. Acesso em: 14 set. 2014; FORTINI, Cristiana; ESTEVES, Júlio César dos Santos; DIAS, Maria Tereza Fonseca (org.). Políticas Públicas: possibilidades e limites. Belo Horizonte: Fórum, 2008; e ZANELLATTO, João Henrique; ESTEVAM, Dimas de Oliveira (org.). Instituições, Políticas Públicas e Desenvolvimento Regional: ensaios temáticos em Ciências Sociais Aplicadas. Criciúma: UNESC, 2013.

${ }^{2}$ GRAU, Eros Roberto. O direito posto e o direito pressuposto. 5a ed. São Paulo: Malheiros, 2003, p. 26. [grifos subtraídos]
} 
para a realização de objetivos socialmente relevantes e politicamente determinados."’3 Aduz, citando Hugo Assman, que políticas públicas “[...] são 'metas coletivas' e, como tais, um problema de direito público, em sentido lato."4

Juarez Freitas, após ressaltar virtudes do conceito de Maria Paula Dallari Bucci, sustenta a necessidade de atrelar esse conceito ao Estado Constitucional, o qual, "[...] numa de suas mais expressivas dimensões pode ser traduzido como o Estado das escolhas administrativas legítimas." Isso promoveria uma constitucionalização das políticas públicas, uma vez que a escolha legítima comunica-se com a interpretação da Constituição e de seus princípios fundamentais. Como resultado, ter-se-ia uma dissociação das políticas públicas das "ações de governo" e sua associação com as "ações de Estado". Desse modo, política pública poderia ser conceituada como "[...] a ação do Estado que intenta articulação eficiente e eficaz dos meios estatais e sociais para cumprir os objetivos vinculantes da Constituição Federal de modo a assegurar, com priorizações fundamentais, a efetividade do conjunto de direitos fundamentais." 6

Algumas conclusões importantes podem ser extraídas desses conceitos. Do primeiro, fundamentalmente, a necessidade de entender que a política pública possui um sentido antes prospectivo que retrospectivo, o qual pode abranger tanto as ações governamentais como a atividade privada, e que essas políticas devem ser exercidas na consecução de objetivos socialmente relevantes. Do segundo, percebe-se, como referido, a necessidade de compreender que as políticas públicas, ligadas mais ao Estado e menos ao Governo, importam em escolhas, notadamente escolhas pela efetividade entre direitos fundamentais conflitantes.

Aliás, feito esse acordo semântico, percebe-se que o conceito de políticas públicas está intimamente ligado ao conceito de interesse público, notadamente partindo do pressuposto - como far-se-á neste estudo - que o interesse público pode ser entendido como

elemento nuclear do Estado que obriga sua ação seja nexo, preferencialmente direto e imediato, da maior realização dos direitos fundamentais, a partir do cumprimento das finalidades do Estado Democrático de Direito estabelecidas em sua Constituição, sendo esse elemento medida da evolução do Estado no sentido do desenvolvimento emancipatório dos seus cidadãos ${ }^{7}$.

Nesse sentido, compreende-se a afirmação de Gerhard Colm:

Em contraste a esses visões [visões que entendem o conceito de interesse público como vago e indeterminado], quero arguir aqui que podemos lidar mais adequadamente com problemas de políticas econômicas e sociais, de finanças públicas e de procedimentos judiciais se enfrentarmos de frente o significado do termo interesse público do que conseguiremos negando esse conceito ou o deixando apenas na porta dos fundos do debate. ${ }^{8}$

\footnotetext{
${ }^{3}$ BUCCI, Maria Paula Dallari. Direito Administrativo e Políticas Públicas. São Paulo: Saraiva, 2002, p. 241.

${ }^{4}$ BUCCI, Maria Paula Dallari. Direito Administrativo e Políticas Públicas. São Paulo: Saraiva, 2002, p. 241.

${ }^{5}$ FREITAS, Juarez. Discricionariedade Administrativa e o Direito Fundamental à Boa Administração Pública. $2^{a}$ ed. São Paulo: Malheiros, 2009, p. 9, grifos invertidos, para preservar sentido original.

${ }^{6}$ FREITAS, Juarez. Transformações do Direito Administrativo, Políticas Públicas e Direito Fundamental à Boa Administração Pública. Informação Verbal. Aula ministrada no Programa de Pós-Graduação da PUCRS, em 04 de setembro de 2012.

${ }^{7}$ HAEBERLIN, Mártin. Uma Teoria do Interesse Público: fundamentos do Estado Meritocrático de Direito. Porto Alegre: Livraria do Advogado, 2017, p. 246.

${ }^{8}$ COLM, Gerhard. The Public Interest: Essential Key to Public Policy. In: FRIEDRICH, Carl (ed.). The Public Interest. New York: Atherton, 1962, p. 117. ("In contrast to these views, I wish to argue here that we can deal more adequately with problems of economic and social policies, public finance, and judicial procedures if we face up squarely to the meaning of the term public interest than if we deny this concept or let in only by the back door.", tradução nossa)
} 
De fato, interesse público e políticas públicas estão jungidas porquanto no cerne dessas duas expressões tão caras ao Direito do Estado e, mais, ao Estado de Direito, encontra-se a busca por um nexo de causalidade entre os meios da ação estatal e a realização de finalidades constitucionais. Comungam-se nelas as "escolhas administrativas legítimas", escolhas essas que devem visar à plena realização das pessoas.

Desde este olhar, os candentes debates sobre a temática das políticas públicas - como aquele da judicialização dos direitos sociais e de seu controle judicial ${ }^{9}$ - são reconsiderados por uma questão anterior, que é aquela da necessidade de um controle de legitimidade dessas políticas. Descortina-se, aqui, a ideia de pensar as políticas públicas no paradigma da emancipação. ${ }^{10}$ Desde esse pano de fundo (de busca por uma "legitimidade emancipatória" das políticas públicas), as chamadas "políticas de mérito" diferenciam-se das políticas públicas convencionais, na visão do autor $^{11}$, por buscarem alternativas não convencionais no sentido de solucionar a constante da colisão de direitos fundamentais, buscando preservar o máximo dos interesses colidentes ao passo que evoluam a sociedade. Para tanto, essas políticas buscam absorver, guardar e superar (aufheben) tanto as concepções intervencionistas e liberais do Estado, pensando a ação estatal desde uma "utopia do realizável"" compasso. ${ }^{13}$ Essa busca por soluções alternativas visa a "[...] adquirir a imaginação institucional, que a Ciência Econômica tem omitido, e insistir na conexão entre a visão do real e a imaginação do possível"14.

${ }^{9}$ Sobre o tema, vide: CARVALHO FILHO, José dos Santos. Políticas Públicas e pretensões judiciais determinativas.
In: FORTINI, Cristiana; ESTEVES, Júlio César dos Santos; DIAS, Maria Tereza Fonseca (org.). Políticas Públicas:
possibilidades e limites. Belo Horizonte: Fórum, 2008; e BUCCI, Maria Paula Dallari. Controle judicial de políticas
públicas: possibilidades e limites. In: Fórum Administrativo: Direito Público, Belo Horizonte, v. 9, n. 103, set. 2009. públicas: possibilidades e limites. In: Fórum Administrativo: Direito Público, Belo Horizonte, ve

${ }^{10}$ Tal desenvolvimento - que é o pano de fundo do presente trabalho -, foi proposto por Mártin Haeberlin, em "Uma Teoria do Interesse Público", e assim apresentado por José Joaquim Gomes Canotilho: "O mérito ligado a políticas públicas não é apenas uma dimensão do controlo de legalidade antes se transmuta em dimensão material de direcção e controlo de legitimidade. Se compreendermos bem a estrutura argumentativa do Autor, o mérito faz parte do "crivo da justiça" ao qual estão sujeitas as políticas públicas, quer no tradicional campo de políticas estatais, quer no âmbito de políticas globais, internacionais e transnacionais. Uma política monetária e financeira, uma política de saúde, uma política de defesa, uma política de informação e comunicação, todas elas saltam das finitudes estatais para se imporem, muitas vezes autoritária ou totalitariamente, negando ou aniquilando o equilíbrio entre a igualdade e a liberdade. Fazem rodar a roda da entropia positiva de programas políticos meritórios, ou esvaziam o princípio do equilíbrio reflexivo ("não egotopia") com consequências trágicas para a constituição, constitucionalização e implementação dos próprios direitos fundamentais. E se o mérito concorre para o teste da "justiça" e da "injustiça" ele deve ser chamado à colação perante a capitulação do "bem comum" e da nossa "casa comum" como o demonstram as tragédias plenas de compaixão diariamente postas ao olhar de todo o mundo. Os direitos humanos, universais, universalizáveis e indivisíveis estão para além dos estados, mas densificam o crivo da justiça aqui, ali, onde quer que esteja, a vertigem tanática contra o ser, sendo pessoa humana." CANOTILHO, José Joaquim Gomes. Prefácio. In: HAEBERLIN, Mártin. Uma Teoria do Interesse Público: fundamentos do Estado Meritocrático de Direito. Porto Alegre: Livraria do Advogado, 2017, p. 14.

${ }^{11}$ HAEBERLIN, Mártin. Uma Teoria do Interesse Público: fundamentos do Estado Meritocrático de Direito. Porto Alegre: Livraria do Advogado, 2017, p. 265-269.

${ }^{12}$ FRIEDMAN, Yona. Utopies Réalisables. Perreux: L'éclat, 2000.

${ }^{13}$ Sobre o tema, vide: UNGER, Roberto Mangabeira. Politics: a work in constructive social theory. Vol 2. Social Theory: its situation and its task. Cambridge: Cambridge University Press, 1990; UNGER, Roberto Mangabeira. Democracy Realized: the progressive alternative. London: Verso, 1998; RUSTIN, Michael. A Practical Utopianism? In: New Left Review, vol. 26, p. 136-47, mar./abr. 2004. Disponível em: <http:// www.law.harvard.edu/faculty/unger/english/pdfs/discussions20.pdf>. Acesso em: 14 set. 2019; GODOY, Arnaldo Sampaio de Moraes. Direito \& Utopia em Roberto Mangabeira Unger: democracia radical, imaginação institucional e esperança como razão. São Paulo: Quartier Latin, 2010.

14 UNGER, Roberto Mangabeira. The Trouble with Economics. Part. 1. Disponível em: <http://www.youtube.com/watch?v=tvzXgWXYmhU>. Acesso em: 14 set. 2014. ("[...] acquiring the institutional Revista de Direito Brasileira | Florianópolis, SC | v. 24 | n. 9 | p.50-67 | Set./Dez. 2019 
Circunstanciadas as noções, Mártin Haeberlin sustenta que as políticas de mérito incorporariam três mandamentos: o equilíbrio entre igualdade e liberdade; a menor entropia; e a não egotopia. ${ }^{15}$ Para os fins desse trabalho, cujo recorte empírico é a judicialização da saúde para a obtenção de medicamentos oncológicos no Estado do Rio Grande do Sul, entendemos oportuno o aporte teórico trazido pelo autor no segundo mandamento, razão pela qual mostra-se necessário entender a noção de entropia e sua relação com as políticas públicas.

\section{A NOÇÃO DE ENTROPIA E SUA IMPORTÂNCIA PARA AS POLÍTICAS PÚBLICAS}

As políticas públicas, enquanto atividades administrativas que visam a conectar os meios disponíveis (atividades estatais) em torno da emancipação das pessoas e dos direitos humanos e fundamentais, são essenciais ao desenvolvimento. Com as políticas públicas, afinal, são buscados resultados práticos na efetivação de bens e interesses coletivos. Uma vez que "um dos modos de pensar o desenvolvimento é, justamente, pensar os problemas que afetam o desenvolvimento"16, a noção de entropia não pode ser desconsiderada. Isso porque, em sistemas sociais que operam meios finitos para obtenção de interesses que tendem ao infinito, a entropia - que se refere exatamente ao desequilíbrio irreversível nos sistemas - é essencial ao entendimento das políticas públicas. Ela é, afinal, uma tendência à desordem (ao não desenvolvimento) exatamente onde a ação estatal busca alguma ordem e progresso.

Por esse motivo, a busca por uma não-entropia (neguentropia) ou por uma menor entropia é uma parte necessária no estudo das políticas públicas, quer desde um ponto de vista jurídico, quer desde um ponto de vista econômico.

No campo do direito, a noção de entropia foi tratada, entre nós, por Pontes de Miranda, em que pese não tenha utilizado explicitamente essa nomenclatura, preferindo falar em uma interpretação biológica da relação jurídica. Assim o fazendo, e alicerçado na ideia de "imperativo energético" de Wilhelm Ostwald e E. Budde, Pontes de Miranda sugeriu a validade, para o sistema jurídico, da proposição: "não desperdice nenhuma energia, mas a aproveite" ("Vergeude keine Energie, aber verwerte sie"). Para o autor, nesse imperativo estaria um protótipo do direito, o qual, ao lidar com os conflitos, impunha "[...] a economia de força, a poupança de esforço, o empenho em resolver as pendências e levar a cabo a igualização das atividades e volições contrárias, com o mínimo gasto de energia." 17 Em ato contínuo, sustentou a existência de dois modos de análise das relações jurídicas: “[...] são relações de adaptação (I), isto é, relações que a exprimem, ou relações que intentam prover à adaptação (II)." 18 Em outras palavras, o direito poderia ser pensado tanto retrospectiva (adaptações já realizadas) como prospectivamente (adaptações desejadas).

Ao tratar de objetos constitucionais - e, fundamentalmente, considerando como "controle de legitimidade" das políticas públicas a sua propensão para a emancipação das pessoas -, evidentemente que o sentido prospectivo de análise das relações jurídicas ganha maior relevo. Nesse sentido, pode-se considerar que a própria visão contemporânea de norma jurídica, a qual não mais se confunde com regras (proposições que predicam hipóteses de incidência razoavelmente identificadas) exatamente por congregar também os princípios jurídicos (mandamentos de

\footnotetext{
imagination, that Economics has lacked, and insisting on the link between insight in to the actual and imagination of the possible.", tradução nossa).

${ }^{15}$ HAEBERLIN, Mártin. Uma Teoria do Interesse Público: fundamentos do Estado Meritocrático de Direito. Porto Alegre: Livraria do Advogado, 2017, p. 269.

${ }^{16}$ HAEBERLIN, Mártin. Uma Teoria do Interesse Público:fundamentos do Estado Meritocrático de Direito. Porto Alegre: Livraria do Advogado, 2017, p. 275.

17 PONTES DE MIRANDA, Francisco Cavalcanti. Sistema de Ciência Positiva do Direito. $2^{\circ}$ ed. Tomo IV Investigação Científica e Intervenção na Matéria Social. Rio de Janeiro: Borsoi, 1972, p. 19.

${ }^{18}$ PONTES DE MIRANDA, Francisco Cavalcanti. Sistema de Ciência Positiva do Direito. $2^{\circ}$ ed. Tomo IV Investigação Científica e Intervenção na Matéria Social. Rio de Janeiro: Borsoi, 1972, p. 20.
}

Revista de Direito Brasileira | Florianópolis, SC | v. 24 | n. 9 | p.50-67 | Set./Dez. 2019 
otimização relacionados a finalidades constitucionais), dotados de força normativa, ostenta a importância das relações jurídicas prospectivas. Para ilustrar essa importância, vale lembrar um marcante exemplo citado por Ronald Dworkin: "[q]uando a Corte decidiu em 1954 que nenhum Estado possuía o direito de segregar escolas públicas por raça, ela levou a nação a uma revolução social mais profunda do que qualquer outra instituição política iniciou ou poderia iniciar.",19 Também a noção de "good governance" alia-se à prospectividade das políticas públicas, pois "[...] a good governance exige que o governo atue de acordo com o interesse público" ${ }^{20}$, cabendo a ele "[...] realizar decisões que avancem o bem comum." 21

Desse modo, o mandamento de menor entropia jurídica - o qual, segundo Mártin Haeberlin, assimilaria o chamado princípio da proibição de retrocesso e nele acrescentaria um sentido positivo (no lugar da não retrocessão, a demanda pelo progresso) - poderia ser definido da seguinte forma: "toda ação retrospectiva (remédios para equilibrar igualdade e liberdade na posição inicial) deve ser conjugada com uma ação prospectiva (programas meritórios) de mesma valência." 22

No campo da economia, a noção de uma menor entropia ${ }^{23}$ envolve o planejamento e a execução de mecanismos de diminuição da escassez, notadamente para, buscando as citadas soluções alternativas, minorar os problemas ínsitos à "reserva do possível"24. Esse planejamento deve ser realizado não exclusivamente, mas essencialmente pelo Estado, em atuação direta no que tange às ações administrativas e indireta no que tange à iniciativa privada. Buscam-se, aqui, inciativas voltadas para a solidariedade e para o incremento do capital social, a fim de que a realização de finalidades constitucionais perca sua dependência, parcial ou totalmente, dos limites orçamentários.

Nesse cenário, na linha do defendido por Roberto Mangabeira Unger, aliar Direito e Economia para que o direito seja uma "ferramenta mestre" no campo da revolução institucional, afastando-se a pobreza auto-imposta do direito atual - motivo pelo qual ele falhou em avançar do seu foco tradicional, da efetivação dos direitos individuais -, para propor o reconhecimento e desenvolvimento de uma "oportunidade institucional transformadora" (transformative institutional oportunity). Fala-se, pois, da necessidade de uma revolução institucional - e constitucional - que alinhe o desenvolvimento humano, econômico e socioambiental, alinhamento do qual não apenas o direito, mas todos os sistemas sociais contemporâneos são, no futuro, dependentes. ${ }^{25}$

A menor entropia econômica, portanto, consagra e densifica a ideia de sustentabilidade, quer no sentido ambiental, quer no sentido econômico-financeiro, em ambos considerando a exigência de, com certa simetria, fazer os cálculos dos problemas do passado e das necessidades do futuro. No plano fiscal, essa lição é bem recolhida nas palavras de Ekkehart Reimer, especialmente ao considerar os tempos de crise:

\footnotetext{
${ }^{19}$ DWORKIN, Ronald. Law's Empire. Cambridge: Harvard University Press, 1986, p. 2. ("When the Court decided in 1954 that no state had the right to segregate public schools by race, it took the nation into a social revolution more profound than any other political institution has, or could have, begun.", tradução nossa)

${ }^{20}$ ELLIOT, Mark; THOMAS, Robert. Public Law. 2a ed. Oxford: Oxford University Press, 2011, p. 343. (“[...] good governance requires that government acts in the public interest.", tradução nossa)

${ }^{21}$ ELLIOT, Mark; THOMAS, Robert. Public Law. 2a ed. Oxford: Oxford University Press, 2011, p. 343. (“[...] government should make decisions that advance the public good.", tradução nossa)

${ }^{22}$ HAEBERLIN, Mártin. Uma Teoria do Interesse Público: fundamentos do Estado Meritocrático de Direito. Porto Alegre: Livraria do Advogado, 2017, p. 278.

${ }^{23}$ Sobre o tema da entropia econômica, vide: HOLDSWORTH, David. Transformational Economics and the Public Good. In: HODGSON, Bernard (ed.). The Invisible Hand and the Common Good. Berlin, Heidelberg: Springer, 2004.

${ }^{24}$ Sobre o tema da reserva do possível, vide: SARLET, Ingo Wolfgang; TIMM, Luciano Benetti (org.). Direitos Fundamentais: orçamento e reserva do possível. Porto Alegre: Livraria do Advogado, 2008.

25. UNGER, Roberto Mangabeira. Legal Analysis as Institutional Imagination. In: The Modern Law Review, vol. 59, n. 1, p. 1-23, jan. 1996.
}

Revista de Direito Brasileira | Florianópolis, SC | v. 24 | n. 9 | p.50-67 | Set./Dez. 2019 
A exigência de simetria refere-se aos efeitos da evolução e obriga os legisladores da Federação e dos Estados a aprovar normas que levem em consideração essa evolução de maneira simétrica. Segundo a vontade do criador da norma, trata-se de garantir, dessa maneira, que o novo endividamento assumido em um período de debilidade conjuntural ver-se-á compensado completamente por meio da correspondente amortização na fase imediatamente posterior em que a conjuntura mostre, novamente, sinais de força. ${ }^{26}$

Como a efetividade de direitos fundamentais por meio de políticas públicas tradicionais possui, usualmente, um alto custo ${ }^{27}$, a menor entropia econômica deve incentivar os mecanismos de autocomposição da sociedade, gerando assim uma blindagem na efetividade desses direitos em relação aos tempos de escassez. Ela remete, assim, à noção de salus populi ("saúde do povo"), a qual Hobbes afirmara ser o "negócio" ("business") do Estado 28.

Avançando na explanação sobre a menor entropia econômica, Mártin Haeberlin sustenta que ela não seria possível "na assunção, pura e simples, de qualquer uma das duas grandes hipóteses econômicas que conhecemos e que, usualmente, entendemos como únicas: o capitalismo liberal e o comunismo marxista." 29 Lembra ele, nesse sentido, que a Igreja Católica, em diferentes textos de sua doutrina social, mostrou-se uma crítica tenaz de ambos, citando o exemplo do Artigo 56 da

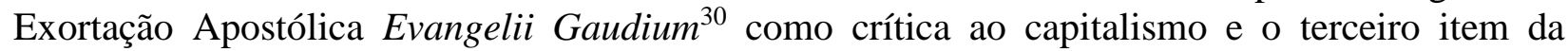
Introdução da Encíclica Rerum Novarum ${ }^{31}$ como crítica ao socialismo, críticas essas referendadas por diversos outros autores.

${ }^{26}$ REIMER, Ekkehart. La Crisis Financiera como Oportunidad Político-Constitucional: el nuevo freno al endeudamiento en la Constitución Alemana. In: Teoría y Realidad Constitucional, n. 28, UNED, p. 93-132, 2011, p. 105-6. ("La exigência de simetría se refiere a los efectos de la evolución y obliga a los legisladores de la Federación y de los Länder a aprobar normas que tomen en consideración esta evolución de manera simétrica. Según la voluntad del creador de la norma, se trata de garantizar de esta manera que el nuevo endeudamiento assumido en un período de debilidade coyuntural se verá completamente compensado por medio de la correspondiente amortización en la fase imediatamente posterior en que la coyuntura muestre de nuevo signos de fortaleza.", tradução nossa)

${ }^{27}$ Cf. HOLMES, Stephen; SUNSTEIN, Cass. The cost of rights: why liberty depends on taxes. New York: W.W. Norton \& Company, 2000.

28 HOBBES, Thomas. Leviathan. Oregon: University of Oregon, 1999, p. 2. Disponível em: <https://scholarsbank.uoregon.edu/xmlui/bitstream/handle/1794/748/leviathan.pdf>. Acesso em: 16 set. 2019.

${ }^{29}$ HAEBERLIN, Mártin. Uma Teoria do Interesse Público: fundamentos do Estado Meritocrático de Direito. Porto Alegre: Livraria do Advogado, 2017, p. 280.

30 "Enquanto os lucros de poucos crescem exponencialmente, os da maioria situam-se cada vez mais longe do bemestar daquela minoria feliz. Tal desequilíbrio provém de ideologias que defendem a autonomia absoluta dos mercados e a especulação financeira. Por isso, negam o direito de controle dos Estados, encarregados de velar pela tutela do bem comum. Instaura-se uma nova tirania invisível, às vezes virtual, que impõe, de forma unilateral e implacável, as suas leis e as suas regras. Além disso, a dívida e os respectivos juros afastam os países das possibilidades viáveis da sua economia, e os cidadãos do seu real poder de compra. A tudo isto vem juntar-se uma corrupção ramificada e uma evasão fiscal egoísta, que assumiram dimensões mundiais. A ambição do poder e do ter não conhece limites. Neste sistema que tende a fagocitar tudo para aumentar os benefícios, qualquer realidade que seja frágil, como o meio ambiente, fica indefesa face aos interesses do mercado divinizado, transformados em regra absoluta." IGREJA CATÓLICA. Papa (2013-: Francisco). Evangelii Gaudium. Roma: Libreria Editrice Vaticana, 2013. Disponível em: $<$ http://w2.vatican.va/ content/francesco/pt/apost_exhortations/documents/papa-francesco_esortazioneap_20131124_evange lii-gaudium.html>. Acesso em: 16 set. 2019.

31 "Os Socialistas, para curar este mal, instigam nos pobres o ódio invejoso contra os que possuem, e pretendem que toda a propriedade de bens particulares deve ser suprimida, que os bens dum indivíduo qualquer devem ser comuns a todos, e que a sua administração deve voltar para - os Municípios ou para o Estado. Mediante esta transladação das propriedades e esta igual repartição das riquezas e das comodidades que elas proporcionam entre os cidadãos, lisonjeiam-se de aplicar um remédio eficaz aos males presentes. Mas semelhante teoria, longe de ser capaz de pôr termo ao conflito, prejudicaria o operário se fosse posta em prática. Pelo contrário, é sumamente injusta, por violar os direitos legítimos dos proprietários, viciar as funções do Estado e tender para a subversão completa do edifício social." IGREJA CATÓLICA. Papa (1878-1903: Papa Leão XIII). Rerum Novarum: sobre a condição dos operários, 1891. Disponível em: <http://www.vatican.va/holy_father/leo_xiii/encyclicals/documents/hf_l-xiii_enc_15051891_rerumnovarum_po.html>. Acesso em: 16 set. 2019.

Revista de Direito Brasileira | Florianópolis, SC | v. 24 | n. 9 | p.50-67 | Set./Dez. 2019 
Na visão de Mártin Haeberlin, porém, ao contrário do que ocorre com os regimes comunistas, os problemas do capitalismo admitiriam uma correção na busca da emenacipação das pessoas, assim afirmando:

Contudo, quer nos parecer que a história, em seu infalível tribunal, atribuiu penas distintas a essas duas hipóteses: enquanto condenou os regimes comunistas à pena capital, ao fundamento da sua total incapacidade de emancipar quaisquer cidadãos vivendo a seus auspícios - exceção feita à emancipação daqueles inseridos aos seus círculos de poder, que provaram tais regimes como reinterpretações hiperbólicas das oligarquias antigas -, condenou os regimes capitalistas a medidas de segurança, ao fundamento cioso da sua incapacidade de gerar o necessário equilíbrio entre igualdade e liberdade, precondição da emancipação em larga escala.

É uma conta fácil, que praticamente pode ser feita apondo dedos da mão contra uma calculadora contábil, aquela que busca por sujeitos emancipados em um e noutro regime, em claro desfavor ao primeiro. O exercício da imaginação institucional, portanto, na razoabilidade que lhe deve ser ínsita, não nega o mercado, nem o potencial emancipador do capital, público e privado, em emancipar os sujeitos. Ao revés, valora-lhe, buscando a maximização desse potencial. Em outras palavras, propõe soluções institucionais alternativas que caminhem junto ao capitalismo, não o humanizando, mas visando a o transformar em sentido humanístico. ${ }^{32}$

A transformação proposta pelo mandamento da menor entropia econômica, desse modo, deveria ocorrer, para o citado autor, em três níveis, quais sejam: o nível da atuação estatal eficiente (envolvendo regulação, atuação fiscal e extrafiscal); o nível da reinterpretação do papel das empresas privadas na sociedade (envolvendo a chamada responsabilidade social); e o nível dos modelos econômicos alternativos (os quais devem ser associados aos anteriores). ${ }^{33}$

Após analisar cada um desses níveis, o autor sugere que o mandamento de menor entropia econômica seja assim definido: "toda ação prospectiva, para integralizar perfeitamente o seu escopo, deve conter, em seu objeto, uma utilidade imediata (contraprestacional) e uma utilidade mediata (sustentável)."34

Como ilustração do mandamento, o autor utiliza o exemplo do Programa Bolsa Família. Nessa análise, lembra, inicialmente, que as políticas públicas "apenas" assistencialistas seriam entrópicas, por lhes faltar prospectividade, uma vez que o suprimento de necessidades básicas é uma atividade prioritária do Estado, mas não gera, por si só, emancipação, devendo ser combinada com mecanismos que possam "reverter a energia" (gasto público) em trabalho (benefício concreto). Sob esse pressuposto, entende que o artigo $3^{\circ}$ da Lei do Bolsa Família, ao determinar que a concessão do benefício possui algumas condicionalidades (exame pré-natal, acompanhamento nutricional e de saúde e frequência escolar), supre o mandamento da menor entropia jurídica, gerando medidas prospectivas junto à retrospectiva (eliminar a pobreza). Todavia, o Programa não satisfaria o mandamento da menor entropia econômica, uma vez que, embora seja nele encontrável uma utilidade imediata (contraprestacional), faltaria a utilidade mediata (sustentável). Diante dessa constatação, sugere que essa sustentabilidade poderia ser alcançada com o aumento do valor do

\footnotetext{
${ }^{32}$ HAEBERLIN, Mártin. Uma Teoria do Interesse Público: fundamentos do Estado Meritocrático de Direito. Porto Alegre: Livraria do Advogado, 2017, p. 280-281.

${ }^{33}$ HAEBERLIN, Mártin. Uma Teoria do Interesse Público: fundamentos do Estado Meritocrático de Direito. Porto Alegre: Livraria do Advogado, 2017, p. 281-284.

${ }^{34}$ HAEBERLIN, Mártin. Uma Teoria do Interesse Público: fundamentos do Estado Meritocrático de Direito. Porto Alegre: Livraria do Advogado, 2017, p. 284.
} 
benefício somado a novas condicionalidades, como o aprendizado de um ofício ou a realização de prestações comunitárias. ${ }^{35}$

\section{O DIREITO À SAÚdE E A POLÍTICA PÚBLICA DE FORNECIMENTO DE MEDICAMENTOS}

No ordenamento jurídico brasileiro, a análise do direito à saúde - do qual deriva a política pública de fornecimento de medicamentos - inicia pelo artigo 196 da Constituição Federal. Tratase de disposição jurídica que provoca a necessidade de compatibilização das teses que sustentam a necessidade de preservação do "mínimo existencial" e a que argumenta pelo respeito à "reserva do possível".

Não obstante o denso debate doutrinário instaurado sobre o alcance da norma constitucional, o percurso aqui proposto busca, inicialmente, identificar como o legislador ordinário organizou a política pública de saúde na área da assistência farmacêutica.

No ano de 1990, foi editada a Lei Federal n. 8.080, que instituiu o Sistema Único de Saúde, atendendo, assim, à exigência imposta pela Constituição Federal. Trata-se de legislação que buscou regular, em todo o território nacional, as ações e serviços de saúde, o que se conclui da literalidade do seu artigo $1^{\circ}$. A assistência farmacêutica integral foi expressamente prevista como incluída no âmbito de atuação do Sistema Único de Saúde (artigo 6º, I, “d”). Mas foi o capítulo VIII da Lei Federal n. 8.080/90, incluído pela Lei Federal n. 12.401/2011, que organizou a assistência terapêutica - nela incluída a farmacêutica - e dispôs sobre incorporação de tecnologias em saúde ao Sistema Único de Saúde.

Em relação à dispensação de medicamentos, deu-se racionalidade à política pública ao se definir que a prescrição deverá estar em conformidade com as diretrizes terapêuticas definidas em protocolos clínicos para as doenças ou agravos em saúde (artigo 19-M, I, primeira parte). Quando não houver protocolo clínico, a dispensação deverá respeitar as relações de medicamentos instituídas pelo gestor federal do SUS e, de forma suplementar, pelos gestores estaduais e municipais, com responsabilidade pelo pactuado na Comissão Intergestores Bipartite, nos Estados, e pelos Conselhos Municipais de Saúde, nos Municípios (artigo 19-P, I a III).

O estabelecimento de protocolos clínicos a serem seguidos no âmbito do SUS deve viabilizar o diagnóstico e o tratamento adequado e isonômico das pessoas que dele necessitam. No que diz respeito aos medicamentos incluídos nos protocolos clínicos, exige-se prévia avaliação quanto à sua eficácia, segurança, efetividade e custo para as diferentes fases evolutivas da doença (artigo 19-O, parágrafo único).

A Comissão Nacional de Incorporação de Novas Tecnologias do SUS (CONITEC) foi criada pela Lei Federal n. 12.401/2011, tendo o Decreto Federal n. 7.646/2011 disposto sobre a sua composição, competências e funcionamento. Trata-se de órgão colegiado de caráter permanente, integrante da estrutura regimental do Ministério da Saúde. A emissão de relatórios e pareceres conclusivos pela CONITEC é atribuição do seu Plenário, o qual é composto de treze membros com direito a voto, sendo eles representantes de órgãos e entidades atuantes na área da saúde ${ }^{36}$.

\footnotetext{
${ }^{35}$ HAEBERLIN, Mártin. Uma Teoria do Interesse Público: fundamentos do Estado Meritocrático de Direito. Porto Alegre: Livraria do Advogado, 2017, p. 284-285.

${ }^{36}$ Art. $7^{\circ}$ O Plenário da CONITEC é composto de treze membros, com direito a voto, representantes dos seguintes órgãos e entidades, indicados pelos seus dirigentes: I - do Ministério da Saúde: a) Secretaria de Ciência, Tecnologia e Insumos Estratégicos do Ministério da Saúde, que o presidirá; b) Secretaria-Executiva; c) Secretaria Especial de Saúde Indígena; d) Secretaria de Atenção à Saúde; e) Secretaria de Vigilância em Saúde; f) Secretaria de Gestão Estratégica e Participativa; e g) Secretaria de Gestão do Trabalho e da Educação na Saúde; II - da Agência Nacional de Saúde Suplementar - ANS; III - da Agência Nacional de Vigilância Sanitária - ANVISA; IV - do Conselho Nacional de Saúde - CNS; V - do Conselho Nacional de Secretários de Saúde - CONASS; VI - do Conselho Nacional de Secretarias Revista de Direito Brasileira | Florianópolis, SC | v. 24 | n. 9 | p.50-67 | Set./Dez. 2019
} 
Ao Plenário da CONITEC compete a emissão de recomendações sobre incorporação, exclusão ou alteração das tecnologias no âmbito do SUS, cabendo ao colegiado, igualmente, manifestar-se acerca da criação ou modificação de protocolos clínicos e diretrizes terapêuticas. Outra relevante competência que lhe é atribuída diz respeito à sua prévia manifestação sobre a atualização da Relação Nacional de Medicamentos Essenciais - RENAME.

O processo administrativo para a incorporação, a exclusão e a alteração pelo SUS de tecnologias em saúde e a constituição ou alteração de protocolos clínicos e diretrizes terapêuticas está descrito no Capítulo II do Decreto Federal n. 7.646/2011. Havendo interesse na incorporação de uma nova tecnologia, a Secretaria-Executiva da CONITEC recebe o pedido e avalia a conformidade da documentação apresentada. Em seguida, ainda na Secretaria-Executiva, são analisados os estudos apresentados pelo interessado e, sendo necessário, podem ser solicitados estudos e pesquisas complementares. O Plenário da CONITEC analisa o relatório, faz recomendações e emite parecer conclusivo. Em seguida, a Secretaria-Executiva submete o parecer à consulta pública e avalia as contribuições obtidas a partir da sua realização. Nesse momento, o Plenário da CONITEC pode ratificar ou retificar a recomendação antes exarada.

A partir da conclusão do Plenário da CONITEC, compete ao Secretário de Ciência, Tecnologia e Insumos Estratégicos avaliar acerca da necessidade de realização de audiência pública, cabendo à Secretaria-Executiva a realização, caso assim decidido. Após todas essas etapas, o Secretário de Ciência, Tecnologia e Insumos Estratégicos analisa o relatório e decide sobre a incorporação, publicando o ato decisório no Diário Oficial da União.

Atualmente, a RENAME encontra-se definida pela Portaria Federal n. 3.047, de 28 de novembro de 2019, a qual objetiva assegurar o acesso da população à assistência farmacêutica e promover o uso racional dos medicamentos no âmbito do SUS.

Não obstante a existência de uma política pública de assistência farmacêutica, verificouse o crescimento exponencial de ações judiciais visando o fornecimento de medicamentos não incluídos na RENAME. As razões para esse fato social são as mais diversas, podendo-se citar, dentre outras, o desconhecimento das listas de medicamentos do SUS pelos médicos prescritores, a demora no processo de incorporação de novos medicamentos e o "lobby" da indústria farmacêutica em favor da utilização das novidades do setor.

Após a propositura de inúmeras ações individuais, a matéria foi decidida pelo Superior Tribunal de Justiça (STJ). A tese afetada a julgamento foi a "obrigatoriedade do poder público fornecer medicamentos não incorporados em atos normativos do SUS". A tese fixada pela Corte para fins do artigo 1.036 do Código de Processo Civil foi a seguinte:

A concessão de medicamentos não incorporados em atos normativos do SUS exige a presença cumulativa dos seguintes requisitos: (i) comprovação, por meio de laudo médico fundamentado e circunstanciado expedido por médico que assiste o paciente, da imprescindibilidade ou necessidade do medicamento, assim como da ineficácia, para o tratamento da moléstia, dos fármacos fornecidos pelo SUS; (ii) incapacidade financeira de arcar com os custos do medicamento prescrito; (iii) existência de registro na ANVISA do medicamento.

O dever de fornecimento de medicamento de alto custo aguarda manifestação conclusiva do Supremo Tribunal Federal (STF), estando a matéria afetada ao regime de repercussão geral ${ }^{37}$.

Municipais de Saúde - CONASEMS; e VII - do Conselho Federal de Medicina - CFM, especialista na área nos termos do $\S 1^{\circ}$ do art. 19-Q da Lei $n^{\circ} 8.080$, de 1990.

${ }^{37}$ Acerca do fornecimento de medicamentos de alto custo por parte do poder público, o STF, em 03 de dezembro de 2007, reconheceu a existência de repercussão geral da questão constitucional no RE 566471 RG / RN, a qual restou cadastrada como Tema 6 (Dever do Estado de fornecer medicamento de alto custo a portador de doença grave que não Revista de Direito Brasileira | Florianópolis, SC | v. 24 | n. 9 | p.50-67 | Set./Dez. 2019 


\section{A POLÍtica PÚBLICA PARA O TRATAMENTO DO CÂNCER E A AUSÊNCIA DE LISTAS DE FORNECIMENTO DE MEDICAMENTOS}

A Política Nacional de Prevenção e Controle do Câncer, instituída pela Portaria Federal n. 874, de 16 de maio de 2013, encontra-se estruturada de modo a oferecer aos usuários ações que permitam a deteç̧ão precoce, o tratamento oportuno e os cuidados paliativos de que necessitam, objetivando, assim, a redução da mortalidade e da incapacidade causadas pela doença e a melhoria da qualidade de vida dos pacientes.

As atividades das Estruturas Operacionais das Redes de Atenção à Saúde subdividem-se em Componente Atenção Básica, Componente Atenção Domiciliar, Componente Atenção Especializada, Componente dos Sistemas de Apoio, Componente Regulação, Componente dos Sistemas Logísticos e Componente Governança.

Não obstante se reconheça a importância dos demais Componentes para que se alcance um tratamento integral e humanizado aos pacientes e famílias que sofrem com a doença, para os fins específicos do presente estudo ganha especial relevo o Componente Atenção Especializada, que se subdivide em Atenção Ambulatorial e Atenção Hospitalar (artigo 26, III, da Portaria Federal n. 874/2013).

É por meio do Componente Atenção Especializado, Atenção Hospitalar, que são oferecidos os tratamentos especializados de alta complexidade e densidade tecnológica para as pessoas com câncer. Esses tratamentos especializados são prestados por entidades hospitalares habilitadas com CACON ou UNACON e pelos Hospitais Gerais com Cirurgia Oncológica. Nos termos do artigo 26, III, $b$, 1, da Portaria Federal n. 874/2013:

Os hospitais habilitados como UNACON são estruturas hospitalares que realizam o diagnóstico definitivo e o tratamento dos cânceres mais prevalentes da região de saúde onde está inserido, enquanto as estruturas hospitalares habilitadas como CACON realizam o diagnóstico definitivo e o tratamento de todos os tipos de câncer, mas não obrigatoriamente dos cânceres raros e infantis.

Além de fornecer procedimentos diagnósticos e terapêuticos de média e alta complexidade não definidos como oncológicos, o SUS financia o tratamento especializado do câncer de forma global, ou seja, tratamento cirúrgico, radioterapia, quimioterapia, iodoterapia e transplantes. $\mathrm{O}$ tratamento cirúrgico, transplantes e iodoterapia, por meio de Autorizações de Internação Hospitalar $(\mathrm{AIH})$ e as quimioterapias e radioterapias mediante Autorização de Procedimentos de Alta Complexidade (APAC). Em outras palavras, pela atual sistemática de custeio, os esquemas terapêuticos e o fornecimento dos medicamentos são responsabilidades dos estabelecimentos devidamente credenciados e habilitados como UNACON, CACON e Hospitais Gerais com Cirurgia Oncológica.

Os medicamentos destinados ao tratamento do câncer não integram as relações de medicamentos do SUS, pois compete ao médico a prerrogativa de prescrever o tratamento que julgar mais adequado. O hospital onde este médico atua (UNACON ou CACON) informa os procedimentos quimioterápicos no SIA-SUS e é ressarcido conforme o código da APAC.

Segundo a Portaria Federal de Consolidação n. 06, de 28 de setembro de 2017, o bloco de financiamento da Atenção de Média e Alta Complexidade Ambulatorial e Hospitalar é constituído por dois componentes: o Componente Limite Financeiro da MAC (Média e Alta Complexidade) e o Componente Fundo de Ações Estratégicas e Compensação - FAEC (artigo 173). O Bloco de Atenção da Média e Alta Complexidade Ambulatorial e Hospitalar é financiado com recursos financeiros federais, nos termos do que dispõe $\S 2^{\circ}$ do artigo 174 da Portaria de Consolidação 
$06 / 2017$.

Ou seja, os estabelecimentos habilitados em Oncologia pelo SUS são os responsáveis pelo fornecimento de medicamentos antineoplásicos que, livremente, padronizam, adquirem e prescrevem. Assim, a partir do momento em que um hospital é habilitado para prestar assistência oncológica pelo SUS, cabe-lhe a responsabilidade pelo fornecimento dos medicamentos antineoplásicos prescritos pelo seu corpo clínico ${ }^{38}$.

\section{PANORAMA DAS AÇÕES JUDICIAIS PARA OBTENÇÃo DE MEDICAMENTOS ONCOLÓGICOS NO ESTADO DO RIO GRANDE DO SUL}

Apresentadas as linhas gerais da política pública de assistência farmacêutica e da Política Nacional de Prevenção e Controle do Câncer, chega-se a duas conclusões: (i) os medicamentos para o tratamento do câncer não fazem parte da política ordinária de assistência farmacêutica, razão pela qual não estão inseridos na RENAME; (ii) o fornecimento desses medicamentos deve ocorrer pelas entidades habilitadas como UNACON e CACON, às quais compete, por meio dos médicos do seu quadro, definir as linhas de tratamento que julgarem mais adequadas.

A despeito da política pública acima apresentada, verifica-se que um número crescente de ações judiciais ajuizadas para obrigar o poder público ao fornecimento de medicamentos para o tratamento do câncer, os quais, na maioria das vezes, apresentam alto custo financeiro. Essas ações judiciais são propostas com o fundamento de que a saúde é um direito assegurado pela Constituição e indissociável do direito à vida, tratando-se de direito público subjetivo constitucionalmente tutelado.

Para o STF, considerando a redação do artigo 196 da Constituição Federal ${ }^{39}$, o polo passivo nas ações que postulam tratamento médico adequado (dentre os quais o tratamento para o câncer) aos necessitados pode ser composto por quaisquer entes federados, isolada ou conjuntamente, na medida em que se trata de uma responsabilidade solidária ${ }^{40}$. Sendo assim, ainda que o ente federativo não detenha competência para gerir ou operacionalizar determinada política pública na área da saúde, admite-se que seja demandado e figure no polo passivo das respectivas ações judiciais.

38 Como exceção, os seguintes antineoplásicos são comprados centralizadamente pelo Ministério da Saúde e distribuídos aos hospitais por meio das secretarias estaduais de saúde: Talidomida para a quimioterapia do Mieloma Múltiplo (Portaria SAS/MS 298/2013, retificada) e da anemia devida a Síndrome Mielodisplásica e resistente à epoetina (Portaria SAS/MS 493/2015); Trastuzumabe para a quimioterapia do carcinoma de mama HER-2 positivo em estágio inicial (I ou II) e para a quimioterapia prévia e adjuvante de carcinoma de mama localmente avançado (estágio III) (portarias SAS/MS 73/2013 e Conjunta SAS e SCTIE/MS 19, de 03/07/2018, e para o tratamento do câncer de mama HER-2 posititvo metastático em primeira linha de tratamento (Portaria Conjunta SAS e SCTIE/MS 5/2019); Pertuzumabe para o câncer de mama HER-2 positivo metastático em primeira linha de tratamento (Portaria Conjunta SAS e SCTIE/MS 5/2019); Mesilato de Imatinibe para a quimioterapia do GIST-Tumor do Estroma Gastrointestinal do adulto (Portaria SAS/MS 494/2014) e para a quimioterapia da LMC-Leucemia Mieloide Crônica (PortariasSAS/MS 114/2012 e 1.219/2013, retificada em 07/01/2015), para a quimioterapia da Leucemia Linfoblástica Aguda (portarias SAS/MS 115/2012 e 312/2013) e da Síndrome Hipereosinofílica (Portaria SAS/MS 783/2015); Dasatinibe e Cloridrato de Nilotinibe para a quimioterapia de $2^{\text {a }}$ linha da LMC (Portaria SAS/MS 103/2015); e Rituximabe para a quimioterapia dos linfomas Difuso de Grandes Células B e Folicular (Portaria SAS/MS 103/2015).

${ }^{39}$ Art. 196. A saúde é direito de todos e dever do Estado, garantido mediante políticas sociais e econômicas que visem à redução do risco de doença e de outros agravos e ao acesso universal e igualitário às ações e serviços para sua promoção, proteção e recuperação.

40 RECURSO EXTRAORDINÁRIO. CONSTITUCIONAL E ADMINISTRATIVO. DIREITO À SAÚDE. TRATAMENTO MÉDICO. RESPONSABILIDADE SOLIDÁRIA DOS ENTES FEDERADOS. REPERCUSSÃO GERAL RECONHECIDA. REAFIRMAÇÃO DE JURISPRUDÊNCIA. O tratamento médico adequado aos necessitados se insere no rol dos deveres do Estado, porquanto responsabilidade solidária dos entes federados. O polo passivo pode ser composto por qualquer um deles, isoladamente, ou conjuntamente. (RE 855178 RG, Relator(a): Min. LUIZ FUX, julgado em 05/03/2015, PROCESSO ELETRÔNICO REPERCUSSÃO GERAL - MÉRITO DJe-050 DIVULG 13-03-2015 PUBLIC 16-03-2015 )

Revista de Direito Brasileira | Florianópolis, SC | v. 24 | n. 9 | p.50-67 | Set./Dez. 2019 
Após a apresentação da Política Nacional de Prevenção e Controle do Câncer no item anterior, verifica-se que os medicamentos oncológicos ou são oferecidos diretamente pelas entidades habilitadas como UNACON ou CACON, as quais recebem recursos do Ministério da Saúde mediante Autorização de Procedimentos de Alta Complexidade (APAC), por se tratar de financiamento da Atenção de Média e Alta Complexidade Ambulatorial e Hospitalar, ou são comprados centralizadamente pelo Ministério da Saúde e distribuídos aos hospitais por meio das Secretarias Estaduais de Saúde.

Não obstante esse papel central da União na promoção da Política Nacional de Prevenção e Controle do Câncer, os entes federativos estaduais e municipais, como referido, seguem sendo demandados para o fornecimento de medicamentos e tratamentos oncológicos. Analisando os dados relativos às ações judiciais ajuizadas em face do Estado do Rio Grande do Sul para o fornecimento de medicamentos oncológicos, verifica-se um número elevado e uma tendência de crescimento.

Segundo dados extraídos do Sistema de Controle de Processos Judiciais da ProcuradoriaGeral do Estado (PGE/RS) ${ }^{41}$, no ano de 2017 foram ajuizadas em face do Estado do Rio Grande do Sul 2.624 novas ações pedindo o fornecimento de medicamentos oncológicos. No ano de 2018, o total de novas ações chegou a 2.645. Em 2019, foram propostas 3.266 novas ações. Esses números ficam ainda maiores se forem consideradas as ações ajuizadas para a obtenção de consultas, cirurgias e internações para tratamento do câncer. Em 2017, foram 3.236 novas ações. O ano de 2018 contou com 3.358 novos processos. Por fim, o ano de 2019 teve 4.122 novos processos relacionados à Política Nacional de Prevenção e Controle do Câncer. Atualmente, tramitam 9.304 processos ajuizados em face do estado do Rio Grande do Sul relacionados ao fornecimento de medicamentos, consultas, cirurgias e internações para o tratamento do câncer.

Em todos esses casos e à luz da Política Nacional de Prevenção e Controle do Câncer, é preciso atentar para a questão jurídica subjacente à análise da política pública. Isso significa identificar se a regra constitucional assegura ao indivíduo o direito subjetivo de acesso a tratamentos/medicamentos cujos valores ultrapassem o limite de custeio individual na forma estabelecida pelo programa de Atenção Oncológica (APAC). Embora a Política Nacional de Prevenção e Controle do Câncer não limite a escolha de medicamentos e terapias, cabendo, como referido, ao médico atuante no UNACON ou CACON a definição do tratamento que julgar mais adequado, a existência de um limite de valor para o ressarcimento pode resultar na limitação dos meios de tratamento. Como consequência, a partir dos limites estabelecidos para o ressarcimento, pode-se ter uma limitação da cobertura em vista dos tipos de terapias disponíveis.

Há, contudo, outro viés de análise, segundo o qual deve-se desprezar a viabilidade financeira de cada tratamento, individualmente, na medida em que, por se tratar de uma política pública, a avaliação deve aferir o equilíbrio financeiro entre os valores repassados ao UNACON/CACON e o montante despendido para a totalidade dos pacientes atendidos em um determinado intervalo de tempo. Existe, nessa perspectiva, um sistema interno de compensação, onde os gastos superiores ao teto de um determinado paciente são compensados com os gastos inferiores ao limite de outro paciente. Em suma, investiga-se se os limites estabelecidos pelo Programa de Atenção Oncológica são constitucionais, verificando se os valores teto permitem a disponibilização de um tratamento oncológico que promova adequadamente o direito fundamental à saúde da totalidade do grupo atendido num determinado período por um mesmo estabelecimento.

O elevado e crescente número de ações judiciais para tratamento do câncer pode resultar de duas situações: (i) subfinanciamento do tratamento do câncer mediante o estabelecimento de limites financeiros insuficientes para o seu custeio; (ii) consideração individualizada do teto de valores para ressarcimento sem avaliar a sustentabilidade financeira do dos tratamentos da totalidade dos pacientes atendidos pela entidade habilitada como UNACON/CACON. As duas

${ }^{41}$ Relatórios extraídos do Sistema CPJ da Procuradoria-Geral do Estado do Rio Grande do Sul em 07/02/2020. Revista de Direito Brasileira | Florianópolis, SC | v. 24 | n. 9 | p.50-67 | Set./Dez. 2019 
hipóteses constituem vícios de execução da política pública, com impacto direto na concretização do direito à saúde.

De um modo ou de outro, a judicialização serve como indicativo de falha no funcionamento da política pública, com consequências no campo jurídico e no campo econômico, demonstrando o afastamento do mandamento proposto neste estudo segundo o qual deve-se buscar uma não entropia ou, não sendo possível evitá-la, a sua diminuição.

Atentando para a menor entropia no campo jurídico, tem-se, como afirmado, que toda ação retrospectiva deve ser conjugada com uma ação prospectiva de mesma valência. Em se tratando da Política Nacional de Prevenção e Controle do Câncer, a ação retrospectiva consiste no fornecimento do tratamento adequado, onde se incluem os medicamentos necessários à realização de quimioterapia, os quais são disponibilizados a todos que deles necessitam, em relação de igualdade. A ação prospectiva centra-se nas medidas capazes de alterar o quadro fático encontrado antes da sua implantação. São ações voltadas à educação e prevenção, enfatizando fatores de proteção em face de agentes cancerígenos físicos e químicos presente no ambiente, bem como comportamentos que potencialmente aumentam o risco de surgimento da doença. Trata-se de estimular e desestimular comportamentos por meio da informação, visando à redução do número de pessoas que desenvolvam a doença.

A necessidade de propor ação judicial para a obtenção do tratamento significa que o usuário não recebeu o medicamento/tratamento diretamente dos hospitais habilitados para a prestação do serviço, resultando no indesejado retardamento para o início da terapêutica, com possíveis reflexos nos resultados obtidos. Evidencia-se, assim, elevada entropia no campo jurídico, em ação retrospectiva, na medida em que os órgãos e entidades competentes deixam de fornecer tempestivamente o medicamento oncológico em razão de vícios na execução da política pública. Nota-se que o problema, assaz grave, mais se relaciona à execução do que à concepção da política pública.

\section{CONCLUSÃO}

Todo estudo sobre políticas públicas deve iniciar por uma compreensão do seu significado. Nesse exercício de realização de um acordo semântico sobre as políticas públicas, encontramos ao menos duas conclusões relevantes: a necessidade de entender que as políticas públicas possuem um sentido antes prospectivo (programático) que retrospectivo, à vista da consecução de objetivos socialmente relevantes; a necessidade de compreender que as políticas públicas, ligadas mais ao Estado e menos ao Governo, importam em escolhas administrativas sobre interesses legítimos, que resultarão na maior ou menor efetividade de alguns direitos humanos e fundamentais. Isso gera uma imbricação entre interesse público e políticas públicas uma vez que, em ambos, encontra-se como cerne a busca por um nexo de causalidade entre os meios da ação estatal e a realização de finalidades constitucionais, em especial a plena realização das pessoas.

A partir desse aporte, o importante capítulo da jurisdição constitucional que se refere ao controle judicial dos direitos sociais, por meio de políticas públicas, urge ser reconsiderado, para se fazer inserir nele a noção de controle de legitimidade, isso é, um controle que pensa as políticas públicas desde o paradigma da emancipação, conforme proposto pela ideia de "políticas de mérito" (Haeberlin). Essas políticas buscam alternativas não convencionais para a a colisão de direitos fundamentais, buscando preservar o máximo dos interesses colidentes ao passo que evoluam a sociedade, exercendo assim uma dialética que absorve, guarda e supera as concepções intervencionistas e liberais do Estado. Do ponto de vista prático, sustentam-se em três mandamentos: o equilíbrio entre igualdade e liberdade; a menor entropia; e a não egotopia.

Para o recorte epistemológico do presente trabalho, entendeu-se oportuno analisar o mandamento na menor entropia. Isso porque a entropia, enquanto geradora de desequilíbrios ns sistemas, mostra-se um entrave ao desenvolvimento, à realização dos direitos humanos e

Revista de Direito Brasileira | Florianópolis, SC | v. 24 | n. 9 | p.50-67 | Set./Dez. 2019 
fundamentais, e à evolução da sociedade. Do ponto de vista jurídico, mostrou-se, a partir do referencial teórico utilizado, que a menor entropia relaciona-se à conjugação entre ações retrospectivas e prospectivas. Já do ponto de vista econômico, ela envolve o planejamento e a execução de mecanismos de diminuição da escassez, associando utilidades imediatas (contraprestacionais) e mediatas (sustentabilidade). Nesse sentido, ela sugere uma transformação em três níveis: atuação estatal eficiente; reinterpretação do papel das empresas privadas na sociedade; utilização de modelos econômicos alternativos.

Partindo-se dessa base teórica relacionada ao mandamento da menor entropia, o presente trabalho realizou um recorte empírico para análise da judicialização da saúde para a obtenção de medicamentos oncológicos no Estado do Rio Grande do Sul.

Dessa análise, constatou-se um crescimento exponencial de ações judiciais visando o fornecimento de medicamentos não incluídos na RENAME, crescimento esse explicado por razões multifatoriais, dentre as quais a decisão do STJ, afetada à sistemática de julgamentos repetitivos, no sentido da "obrigatoriedade do poder público fornecer medicamentos não incorporados em atos normativos do SUS", obedecidos alguns requisitos analisados no texto. No caso específico do câncer, o elevado e crescente número de ações judiciais para tratamento pode resultar de duas situações: (i) subfinanciamento do tratamento do câncer mediante o estabelecimento de limites financeiros insuficientes para o seu custeio; e (ii) consideração individualizada do teto de valores para ressarcimento sem avaliar a sustentabilidade financeira do dos tratamentos da totalidade dos pacientes atendidos pela entidade habilitada como UNACON/CACON. As duas hipóteses constituem vícios de execução da política pública, com impacto direto na concretização do direito à saúde.

A judicialização serve, pois, como um indicativo de falha no funcionamento da política pública, com consequências no campo jurídico e no campo econômico, demonstrando o afastamento do mandamento de menor entropia. Veja-se que, em se tratando da Política Nacional de Prevenção e Controle do Câncer, a ação retrospectiva consiste no fornecimento do tratamento adequado, onde se incluem os medicamentos necessários à realização de quimioterapia, os quais são disponibilizados a todos que deles necessitam. Já a ação prospectiva contempla medidas capazes de alterar o quadro fático encontrado antes da sua implantação, em ações voltadas à educação e prevenção.

Diante do quadro analisado, percebe-se, além da incipiência de ações prospectivas, os reflexos negativos das ações retrospectivas (centradas no fornecimento de medicamento). Isso porque o ajuizamento de milhares de ações judiciais visando à obtenção de tratamentos que deveriam ser oferecidos administrativamente, movimenta recursos financeiros e humanos -sempre escassos - para finalidades diversas daquelas originalmente previstas na política pública vigente, gerando um círculo vicioso de desorganização administrativa e desperdício de energia.

\section{REFERÊNCIAS}

BREUS, Thiago Lima. Políticas Públicas no Estado Constitucional: problemática da concretização dos direitos fundamentais pela Administração Pública brasileira contemporânea. Belo Horizonte: Fórum, 2007.

BUCCI, Maria Paula Dallari. Direito Administrativo e Políticas Públicas. São Paulo: Saraiva, 2002.

BUCCI, Maria Paula Dallari (org.). Políticas Públicas: reflexões sobre o conceito. São Paulo: Saraiva, 2006. 
BUCCI, Maria Paula Dallari. Controle judicial de políticas públicas: possibilidades e limites. In: Fórum Administrativo: Direito Público, Belo Horizonte, v. 9, n. 103, set. 2009. Disponível em: <http://bdjur.stj.jus.br/dspace/handle/2011/32047>. Acesso em: 14 set. 2014.

CANOTILHO, José Joaquim Gomes. Prefácio. In: HAEBERLIN, Mártin. Uma Teoria do Interesse Público: fundamentos do Estado Meritocrático de Direito. Porto Alegre: Livraria do Advogado, 2017.

CARVALHO FILHO, José dos Santos. Políticas Públicas e pretensões judiciais determinativas. In: FORTINI, Cristiana; ESTEVES, Júlio César dos Santos; DIAS, Maria Tereza Fonseca (org.). Políticas Públicas: possibilidades e limites. Belo Horizonte: Fórum, 2008.

COLM, Gerhard. The Public Interest: Essential Key to Public Policy. In: FRIEDRICH, Carl (ed.). The Public Interest. New York: Atherton, 1962.

DWORKIN, Ronald. Law’s Empire. Cambridge: Harvard University Press, 1986.

ELLIOT, Mark; THOMAS, Robert. Public Law. 2ª ed. Oxford: Oxford University Press, 2011.

FORTINI, Cristiana; ESTEVES, Júlio César dos Santos; DIAS, Maria Tereza Fonseca (org.). Políticas Públicas: possibilidades e limites. Belo Horizonte: Fórum, 2008.

FREITAS, Juarez. Discricionariedade Administrativa e o Direito Fundamental à Boa Administração Pública. $2^{a}$ ed. São Paulo: Malheiros, 2009.

FREITAS, Juarez. Transformações do Direito Administrativo, Políticas Públicas e Direito Fundamental à Boa Administração Pública. Informação Verbal. Aula ministrada no Programa de Pós-Graduação da PUCRS, em 04 de setembro de 2012.

FRIEDMAN, Yona. Utopies Réalisables. Perreux: L’éclat, 2000.

GRAU, Eros Roberto. $O$ direito posto e o direito pressuposto. $5^{\text {a }}$ ed. São Paulo: Malheiros, 2003.

GODOY, Arnaldo Sampaio de Moraes. Direito \& Utopia em Roberto Mangabeira Unger: democracia radical, imaginação institucional e esperança como razão. São Paulo: Quartier Latin, 2010 .

HAEBERLIN, Mártin. Uma Teoria do Interesse Público: fundamentos do Estado Meritocrático de Direito. Porto Alegre: Livraria do Advogado, 2017.

HOBBES, Thomas. Leviathan. Oregon: University of Oregon, 1999. Disponível em: <https://scholarsbank.uoregon.edu/xmlui/bitstream/handle/1794/748/leviathan.pdf>. Acesso em: 16 set. 2019. 
HOLDSWORTH, David. Transformational Economics and the Public Good. In: HODGSON, Bernard (ed.). The Invisible Hand and the Common Good. Berlin, Heidelberg: Springer, 2004.

HOLMES, Stephen; SUNSTEIN, Cass. The cost of rights: why liberty depends on taxes. New York: W.W. Norton \& Company, 2000.

IGREJA CATÓLICA. Papa (1878-1903: Papa Leão XIII). Rerum Novarum: sobre a condição dos operários, 1891. Disponível em: <http://www.vatican.va/holy_father/leo_xiii/encyclicals/ documents/hf_l-xiii_enc_15051891_rerum-novarum_po.html>. Acesso em: 16 set. 2019.

IGREJA CATÓLICA. Papa (2013-: Francisco). Evangelii Gaudium. Roma: Libreria Editrice Vaticana, 2013. Disponível em: <http://w2.vatican.va/ content/francesco/pt/apost_exhortations/documents/papa-francesco_esortazioneap_20131124_evange lii-gaudium.html>. Acesso em: 16 set. 2019.

PONTES DE MIRANDA, Francisco Cavalcanti. Sistema de Ciência Positiva do Direito. $2^{\circ}$ ed. Tomo IV - Investigação Científica e Intervenção na Matéria Social. Rio de Janeiro: Borsoi, 1972.

REIMER, Ekkehart. La Crisis Financiera como Oportunidad Político-Constitucional: el nuevo freno al endeudamiento en la Constitución Alemana. In: Teoría y Realidad Constitucional, $n$. 28, UNED, p. 93-132, 2011.

RUSTIN, Michael. A Practical Utopianism? In: New Left Review, vol. 26, p. 136-47, mar./abr. 2004. Disponível em: <http://

www.law.harvard.edu/faculty/unger/english/pdfs/discussions20.pdf>. Acesso em: 14 set. 2019.

SARLET, Ingo Wolfgang; TIMM, Luciano Benetti (org.). Direitos Fundamentais: orçamento e reserva do possível. Porto Alegre: Livraria do Advogado, 2008.

UNGER, Roberto Mangabeira. Politics: a work in constructive social theory. Vol 2. Social Theory: its situation and its task. Cambridge: Cambridge University Press, 1990.

UNGER, Roberto Mangabeira. Democracy Realized: the progressive alternative. London: Verso, 1998.

UNGER, Roberto Mangabeira. The Trouble with Economics. Part. 1. Disponível em: <http://www.youtube.com/watch?v=tvzXgWXYmhU>. Acesso em: 14 set. 2014.

UNGER, Roberto Mangabeira. Legal Analysis as Institutional Imagination. In: The Modern Law Review, vol. 59, n. 1, p. 1-23, jan. 1996.

ZANELlATTO, João Henrique; ESTEVAM, Dimas de Oliveira (org.). Instituições, Políticas Públicas e Desenvolvimento Regional: ensaios temáticos em Ciências Sociais Aplicadas. Criciúma: UNESC, 2013. 